ein, welche nicht dickere Gefässbündel enthalten. Die Mitte des Blattes wird von den meist nur ca, $1 / 7$ des Blattdurchmessers einnehmenden Gefässbündeln gebildet, welche zwischen den grossen

Solenostemma Arghel Heyne. Elemente des mit Weingeist extrahirten Blattpulvers.
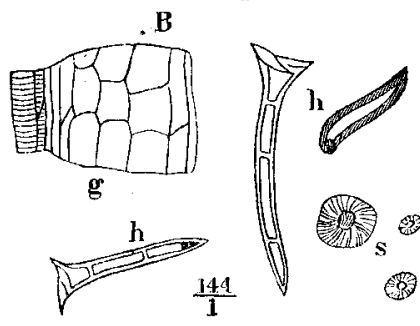

g. Stückchen Gefässbündel.

h. Haare.

s. Kugelige Steinzellen. rundlichen Zellen des inneren Blattparemchyms eingelagert sind. Besonders an der Unterseite des grossen Blattnerven, aber auch sonst unter der Epidermis und tiefer im pallisadenähnlichen Gewebe liegen kuglige Steinzellen (s. Fig. B) von sehr verschiedener Grösse. Diese, die eigenthiumlichen Haare und die Epidermisfragmente (deren Stomata Fig. A im Pulver kaum mehr erkennbar sind), geben dem Bilde des Pulvers seinen Charakter. Fig. B zeigt die hauptsächlichsten Elemente des mit siedendem Alkohol extrahirten Pulvers, jedoch mit Ausnahme der bereits Fig. A abgebildeten Epidermis-Fragmente. ${ }^{1}$ Die Gefässbündel (g Fig. B) bieten auch hier nichts Charakteristisches. ${ }^{2}$

\title{
Argentinisches (Kemmerichs) Fleischextract von Sta. Elena.
}

Von Dr. Niederstadt in Hamburg.

Die Herstellung des Fleischextractes datirt seit der Zeit, dass man bei Kranken und Reconvalescenten einen kalten wässrigen Fleischauszug in Anwendung brachte; es geschah dieses namentlich auf Liebig's Empfehlung in München. Seit dem Jahre 1864 kam in Uruguay in Fray Bentos die erste Fleischextractfabrik in Betrieb. Später folgten andere, deren Präparate sich stets nützlicher und vortheilhafter für den Consum erwiesen. Im Jahre 1872 wurden mehr als 540,000 Kilog. Fleischextract von mehreren Fabriken in den Handel gebracht, welcher Verbrauch stetig zugenommen hat.

1) Nach einem Glycerinpräparat gezeichnet.

2) Der Maassstab S. 109 kann bei beidèn Figuren auch hier benutzt werden. 
Das Ausziehen des Fleisches, welches von Fett aufs sorgfältigste befreit wird, hat in practischer Art zu geschehen, um Leim zurückzuhalten. Die Haltbarkeit solches Extractes wird wesentlich befördert, wie es beim vorliegenden der Fall ist, wenn Leim und Fett so gut wie ganz fehlen. Unter den Fleischextracten, die in neuerer Zeit in den Handel gebracht sind, befindet sich das von den Herren E. Kemmerich \& Co. in Sta. Elena in Argentinien hergestellte.

Der Inhaber dieses Etablissements, Professor Dr. Kemmerich, hatte vorher Gelegenheit sich reiche Erfahrung bei der Herstellung des Extracts zu erwerben und ist das dortige Präparat aufs sorgfältigste bereitet. Das hellbraune Extract besitzt einen kräftigen reinen Fleischgeruch und Geschmack nach frischem Gebratenen. In letzter Zeit sind mehrere Untersuchungen des Extractes ausgefuhrt worden und zwar fand:

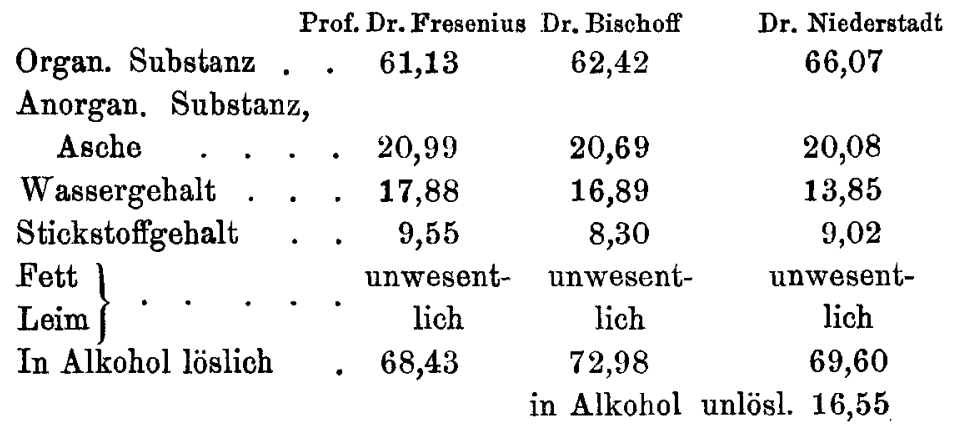

Die Asche besteht aus:

\begin{tabular}{|c|c|c|c|c|}
\hline Eisenoxyd & . & Spur & 0,22 & 0,32 \\
\hline Kalk & . . & 0,43 & 0,52 & 1,76 \\
\hline Magnesia & . . . & 2,86 & 3,89 & 2,03 \\
\hline Natron & . . . & 11,63 & 11,51 & 11,32 \\
\hline Kali . . . & . . . & 44,26 & 41,79 & 44,04 \\
\hline Chlor & . . & 8,34 & 9,46 & 8,36 \\
\hline Schwefelsäure & . . & 1,77 & 1,54 & 1,62 \\
\hline Phosphorsäure & . . & 32,35 & 32,55 & 32,12 \\
\hline Kieselsäure . & . . . & 0,24 & 0,82 & 0,31 \\
\hline & & 101,88 & 102,30 & 101,88 Sauerstoff \\
\hline \multirow[t]{2}{*}{$\mathbf{a b}$} & Chlor & 1,88 & & 1,88 abf. Chlor \\
\hline & & 100,00 & & 100,00 \\
\hline
\end{tabular}


Die Proteïne, welche also die Stickstoffsubstanz des Fleischextracts ausmachen, sind beim Vergleich mit einigen der gebräuchlichsten Extracte in grösserer Menge als anderswo in benannten vorhanden.

Bei 9,02 Proc. Stickstoff sind im Extract 56,37 Proc. Proteïne enthalten; sie bestehen aus Kreatin, Syntonin, Sarkosin, Fibrin und anderen, und machen die directen blut-, muskel- und nervenbildenden Stoffe des Körpers aus. Mit Wasser giebt das Extract eine fast völlig klare braune Flüssigkeit.

\section{Ueber die Samenschale der Coloquinthe.}

C. Hartwich in Tangermünde.

Ist der Same der Coloquinthe auch nicht derjenige Theil, der pharmaceutische Verwendung "findet, so bleibt nichts desto weniger die Kenntniss der Droge ohne ihn eine unvollständige. Soviel mir bekannt, hat die anatomische Untersuchung der Coloquinthe bis jetzt sich meist auf die Fruchtschale und das Mark beschränkt, während der Same etwas stiefmütterlich behandelt wurde und doch ist der Bau besonders seiner Samenschale wie bei allen Cucurbitaceen ein recht interessanter. Es findet sich zwar in dieser Zeitschrift 1872 p. 235 eine Arbeit von Flückiger „die Coloquinthe als Nährpflanze", in der eine Beschreibung und Abbildung der anatomischen Verhältnisse der Samenschale enthalten ist, wahrsoheinlich hat aber Flückiger den Bau der Samenschale nur auf Querschnitten studirt, sodass ihm eine Anzahl Details, die erst an Macerationspräparaten und Tangentialschnitten hervortreten, entgangen sind; ferner sind seither einige treffliche Arbeiten über die Entwicklungsgeschichte der Samenschale der Cucurbitaceen (v. Höhnel, Morphologische Untersuchungen über die Samenschalen der Cucurbitaceen und einiger verwandter Familien. - Sitzungsberichte der kaiserl. Akademie d. Wissenschaften. Band LXXIII. Wien 1876. - Fickel, über die Anatomie und Entwicklungsgeschichte der Samenschale einiger Cucurbitaceen. Botan. Zeitung 1876) erschienen, die es ermöglichen, Einzelnheiten, die an der reifen Teste leicht übersehen, sicher zu erkennen und die es gestatten, von jeder einzelnen Zellschicht mit Sicherheit nachzuweisen, aus 